\title{
World Journal of Pediatric Surgery \\ Use of transabdominal (external) ultrasound during balloon dilatation to diagnose tracheobronchial remnant in congenital esophageal stenosis
}

Kengo Hattori, ${ }^{1}$ Shigeru Takamizawa, ${ }^{1}$ Yuichiro Miyake, ${ }^{1}$ Tomoko Hatata, ${ }^{1}$ Katsumi Yoshizawa, ${ }^{1}$ Tomoko Furukawa, ${ }^{2}$ Yoshiaki Kondo ${ }^{2}$

To cite: Hattori $\mathrm{K}$, Takamizawa S, Miyake Y, et al. Use of transabdominal (external) ultrasound during balloon dilatation to diagnose tracheobronchial remnant in congenital esophageal stenosis. World Jnl Ped Surgery 2018;1:e000006. doi:10.1136/ wjps-2018-000006

Accepted 7 November 2018

Check for updates

(c) Author(s) (or their employer(s)) 2018. Re-use permitted under CC BY-NC. No commercial re-use. See rights and permissions. Published by BMJ.

${ }^{1}$ Department of Surgery, Nagano Children's Hospital, Nagano, Japan

2Department of Radiology, Nagano Children's Hospital, Nagano, Japan

Correspondence to Dr Kengo Hattori; ken5hattori@ gmail.com

\section{ABSTRACT}

Preoperativedifferential diagnosis between tracheobronchial remnant (TBR) and other typesof congenital esophageal stenosis (CES) is challenging, even when usingendoscopic ultrasonography (EUS). This report is the first to demonstrate theuse of transabdominal (external) ultrasound during balloon dilatation todiagnose TBR in CES. This simple technique is a promising diagnostic tool forTBR as an alternative to EUS.

\section{INTRODUCTION}

Congenital esophageal stenosis (CES) is a rare malformation which can be caused by tracheobronchial remnants (TBR), fibromuscular thickening (FM), or membranous web. The TBR type of CES typically requires definitive surgical resection because endoscopic dilatations for this type tend to fail. ${ }^{1}$ Previous reports have suggested that preoperative differential diagnosis between TBR and the other two types by fluoroscopy or esophagoscopy is nearly impossible, but that endoscopic ultrasonography (EUS) could demonstrate specific features of TBR at the site of stenosis. However, the performance of EUS in children remains challenging and a simpler diagnostic tool is needed. Here, we report a case of the TBR type of CES preoperatively diagnosed by transabdominal (external) ultrasound (TAUS) during balloon dilatation. To our knowledge, this is the first report of a diagnosis of TBR in CES by TAUS during balloon dilatation, and we believe that this method may be a promising diagnostic tool for TBR as an alternative to EUS.

\section{CASE PRESENTATION}

A 1-year-old girl presented with intermittent vomiting and failure to thrive after the initiation of weaning. Fluoroscopy showed an abrupt narrowing, immediately above the esophagogastric junction with suprastenotic dilatation and proximal ring (figure 1). A flexible endoscope with a distal end diameter of $5.4 \mathrm{~mm}$ (GIF TYPE XP260NS; Olympus Medical Systems, Tokyo, Japan) could pass the proximal esophageal ring easily; it was used to identify a circumferential, slightly non-central, pinhole narrowing, just above the esophagogastric junction; this narrowing did not show signs of esophagitis or reflux (figure 2). With the diagnosis of CES, the patient underwent two unsuccessful endoscopic balloon dilatation procedures. During the second dilatation under general anesthesia, we performed TAUS using portable ultrasound equipment (Noblus; Hitachi Aloka Medical, Tokyo, Japan) with a linear array transducer 5-18 MHz. The distal esophagus could be identified behind the left lobe of the liver. When the balloon (CRE Wireguided Balloon Dilator; Boston Scientific, Natick, Massachusetts, USA) was guided to the stenotic site and inflated with dilute contrast medium (up to $9 \mathrm{~mm}$ under fluoroscopic control), the stenotic site was clearly visualized by the TAUS scan, angled cephalad from the epigastric region, just below the sternum. It clearly revealed discontinuity of the hypoechoic muscle layer with multiple echogenic regions, suggesting cartilage at the stenosis (figure 3A,B). In accordance with these observations, we diagnosed the patient with a TBR type of CES and performed laparoscopic surgery. During the operation, we confirmed the stenotic site with the balloon inflated under fluoroscopy after the anterior esophageal dissection. A partial resection of the anterior esophageal wall was performed at the stenotic site using scissors with electrocautery, followed by a transverse suture to the longitudinal axis of the esophagus and the anterior Dor fundoplication. Histologic examination of the resected specimen 


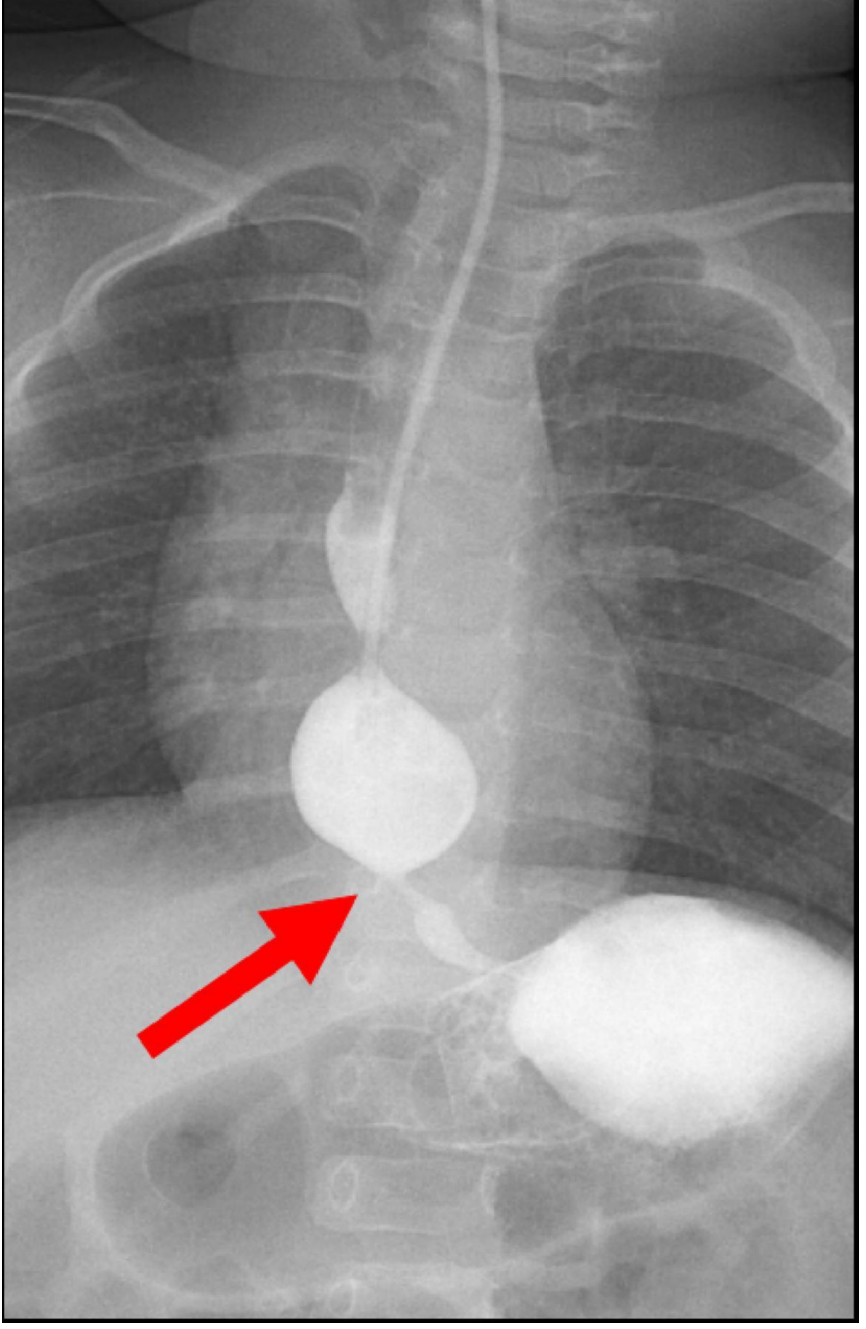

Figure 1 Fluoroscopy showed an abrupt narrowing (arrow) immediately above the esophagogastric junction, with suprastenotic dilatation and proximal ring.

showed cartilage and mucus glands of bronchial origin, confirming TBR (figure 4).

\section{DISCUSSION}

Some reports have insisted that an abrupt stenosis on esophagogram correlated with the TBR type of CES and a tapered stenosis occurred in FM; however, this was disproved by recent studies. ${ }^{2}$ Esophagoscopy can indeed visualize a membranous web; otherwise, it simply shows a non-yielding stenosis with a normal smooth mucosal lining in CES. Endoscopic biopsy specimens are usually non-specific. ${ }^{3}$ Further imaging modalities, including CT scan and MRI, are not useful for detecting TBRs. ${ }^{3}$ In the present case, we also performed MRI, but could not identify TBRs.

Since the early 2000s, EUS has become available for use in small children, with miniprobes inserted through the operative channel of the endoscope, and allows for the detailed evaluation of the esophageal wall at the level of the stenosis; this enables clinicians to distinguish between TBR and FM. ${ }^{145} \mathrm{~A}$

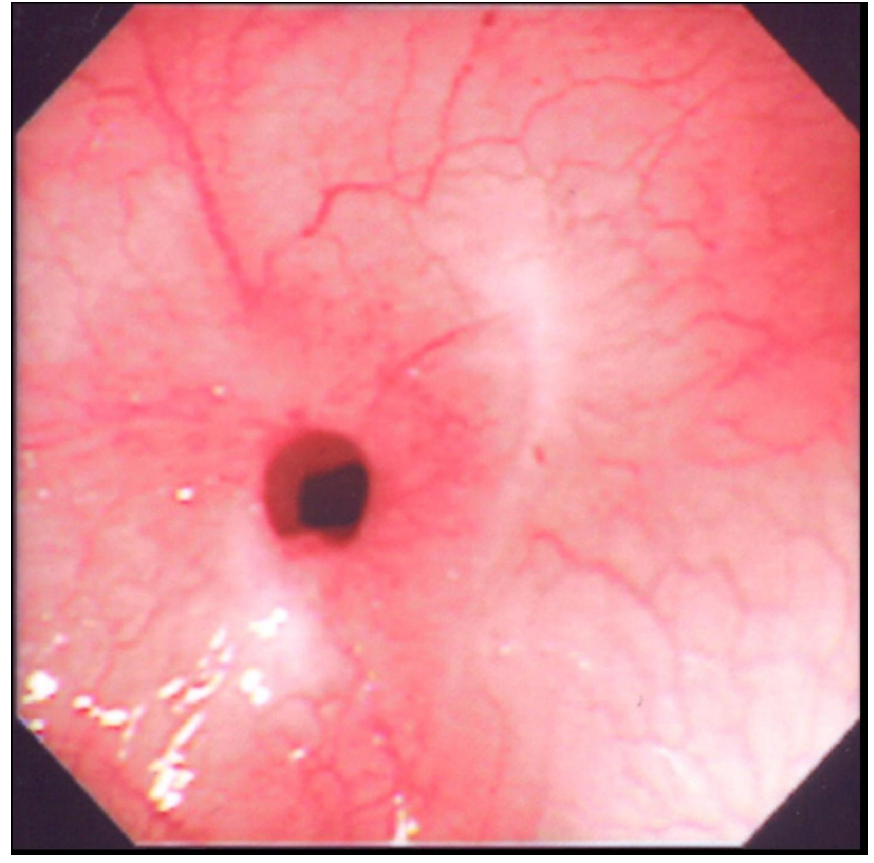

Figure 2 Flexible endoscopic image of a circumferential narrowing immediately above the esophagogastric junction, with normal mucous membrane lining the esophagus.

high correlation between EUS visualization of TBR and surgical findings has been proven. ${ }^{6}$ In TBR, there are commonly multiple echogenic regions within the muscle layer that represent aberrant cartilaginous remnants. The echogenicity and feature of the cartilage vary by report, including the following: a sonolucent area in the fourth layer, ${ }^{1}$ multiple low echoic regions in the focally thickened muscularis propria layer, ${ }^{5}$ thickened hypoechoic area made of cartilaginous material, ${ }^{7}$ hyperechoic lesions just underneath the mucosa and deep in the muscle layer, ${ }^{4}$ a complete hyperechoic ring outside the esophageal wall, ${ }^{3}$ hyperechoic lesions with acoustic shadow within the thickened segment, ${ }^{8}$ and little hyperechoic areas in the muscular layer. ${ }^{6}$ In the present case, we could observe the hypoechoic muscle layer with echogenic regions

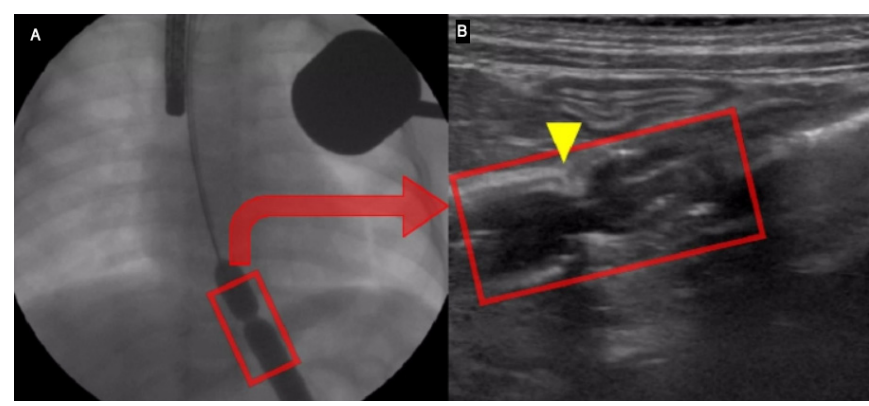

Figure 3 Transabdominal (external) ultrasound (TAUS) during balloon dilatation. (A) Fluoroscopy image during balloon dilatation (up to $9 \mathrm{~mm}$ ). (B) Image of TAUS with the balloon inflated: discontinuity of the hypoechoic muscle layer with echogenic regions, suggesting cartilage at the stenosis (arrowhead). 


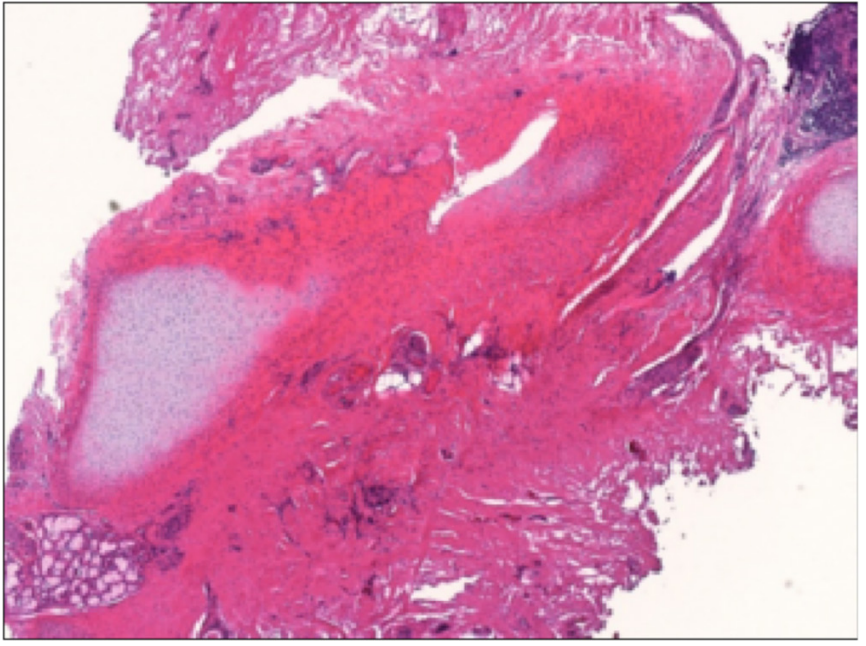

Figure 4 Histologic examination of the resected specimen: cartilage and mucus glands of bronchial origin confirming tracheobronchial remnant.

during TAUS. Further studies are needed to define the sonographic features of TBRs, which might depend on maturity of the cartilage.

Another limitation of TAUS for esophagus is the presence of air. TAUS can depict only the lower esophagus, especially in the context of the proximity of the gastroesophageal junction in the abdomen. Fortunately, the TBR type of CES commonly occurs in the distal one-third of the esophagus, especially $1-2 \mathrm{~cm}$ above the gastroesophageal junction. Furthermore, the inflated balloon dilator can lower the stenotic lesion into the abdomen.

In conclusion, our case suggested that this simple technique of TAUS, with the familiar image orientation of external ultrasound, is a promising diagnostic tool for TBR as an alternative to EUS.
Contributors $\mathrm{KH}$ designed the study and wrote the initial draft of the manuscript. ST, TF, and YK contributed to analysis and interpretation of data, and assisted in the preparation of the manuscript. All other authors have contributed to data collection and interpretation, and critically reviewed the manuscript. All authors approved the final version of the manuscript, and agree to be accountable for all aspects of the work in ensuring that questions related to the accuracy or integrity of any part of the work are appropriately investigated and resolved.

Funding The authors have not declared a specific grant for this research from any funding agency in the public, commercial or not-for-profit sectors.

Competing interests None declared.

Patient consent Parental/guardian consent obtained.

Ethics approval The Ethics Committee at Nagano Children's Hospital.

Provenance and peer review Not commissioned; externally peer reviewed.

Open access This is an open access article distributed in accordance with the Creative Commons Attribution Non Commercial (CC BY-NC 4.0) license, which permits others to distribute, remix, adapt, build upon this work non-commercially, and license their derivative works on different terms, provided the original work is properly cited, appropriate credit is given, any changes made indicated, and the use is non-commercial. See: http://creativecommons.org/licenses/by-nc/4.0

\section{REFERENCES}

1. Takamizawa S, Tsugawa C, Mouri N. Congenital esophageal stenosis: therapeutic strategy based on etiology. J Pediatr Surg 2002;37:197-201.

2. Amae S, Nio M, Kamiyama T, et al. Clinical characteristics and management of congenital esophageal stenosis: a report on 14 cases. J Pediatr Surg 2003;38:565-70.

3. Bocus P, Realdon S, Eloubeidi MA, et al. High-frequency miniprobes and 3-dimensional EUS for preoperative evaluation of the etiology of congenital esophageal stenosis in children (with video). Gastrointest Endosc 2011;74:204-7.

4. Usui N, Kamata S, Kawahara H. Usefulness of endoscopic ultrasonography in the diagnosis of congenital esophageal stenosis. $J$ Pediatr Surg 1744;2002:37.

5. Kouchi K, Yoshida H, Matsunaga T, et al. Endosonographic evaluation in two children with esophageal stenosis. J Pediatr Surg 2002;37:934-6.

6. Romeo E, Foschia F, de Angelis P, et al. Endoscopic management of congenital esophageal stenosis. J Pediatr Surg 2011;46:838-41.

7. Banerjee N, Adler DG. Endoscopic ultrasound in pediatric patients. Techniques in Gastrointestinal Endoscopy

8. Serrao E, Santos A, Gaivao A, et al. Congenital esophageal stenosis: a rare case of dysphagia. J Radiol Case Rep 2010;4:8. 